\title{
Nuclear Projections in Neutrophils for Supporting the Diagnosis of Trisomy 13
}

Trisomi 13 Tanısını Desteklemede Nötrofillerdeki Nükleer Çıkıntılar

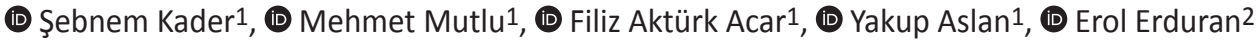 \\ ${ }^{1}$ Karadeniz Technical University Faculty of Medicine, Division of Neonatology, Trabzon, Turkey \\ ${ }^{2}$ Karadeniz Technical University Faculty of Medicine, Division Pediatric Hematology, Trabzon, Turkey
}

To the Editor,

Trisomy 13 is a rare genetic disorder characterized by severe multiple congenital anomalies. Structural anomalies of neutrophils may be supportive for the diagnosis of trisomy 13 .

A newborn was born by vaginal delivery after 29 weeks of pregnancy. Physical examination revealed symmetric growth restriction, low-set hypoplastic ears, aplasia cutis congenita areata on the vertex, postaxial polydactyly of the foot, bilateral microphthalmia, an umbilical cord cyst, and heart murmurs. Echocardiography showed truncus arteriosus type I. Review of the peripheral blood smear revealed two or more small threadlike pedunculated projections attached to the surface of the nuclei in more than $60 \%$ of the neutrophils (Figure 1). The diagnosis of trisomy 13 was made by chromosomal analysis. The infant died at 2 days of life because of massive pulmonary hemorrhage.

The presence of threadlike pedunculated projections attached to the surface of the nuclei of neutrophils was described in trisomy of the D group of chromosomes $(13,14$, and 15) and also in trisomy $18[1,2]$. Two or more nuclear projections detected in more than $15 \%$ of neutrophils may be highly suggestive of these trisomies [3]. We suggest that identification of characteristic structural anomalies of neutrophils on a blood smear may be used for supporting the diagnosis of these trisomies.

Keywords: Trisomy 13, Blood smear, Neutrophilic nuclear projections

Anahtar Sözcükler: Trisomi 13, Periferik yayma, Nötrofilik nükleer projeksiyon

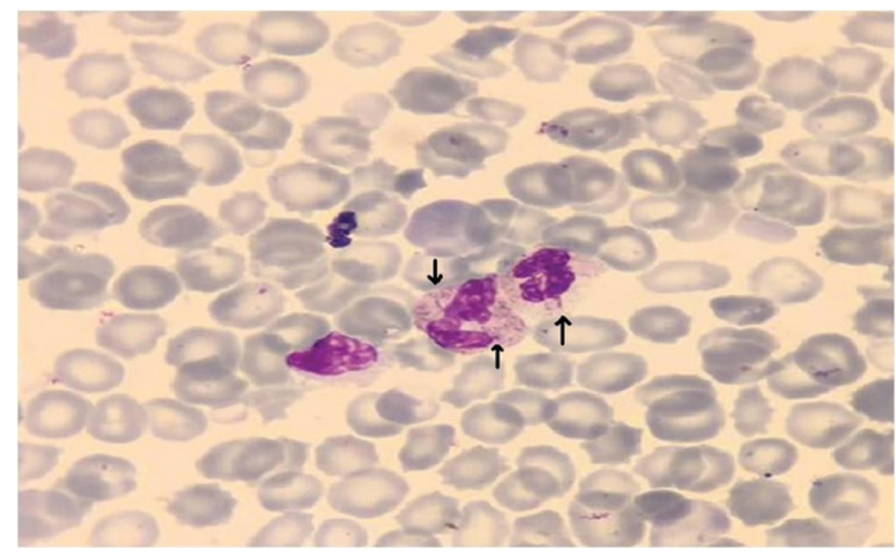

Figure 1. Peripheral blood smear showing threadlike pedunculated projections attached to the surface of the nuclei of neutrophils.

Informed Consent: Our patient's parent gave consent.

Conflict of Interest: The authors of this paper have no conflicts of interest, including specific financial interests, relationships, and/or affiliations relevant to the subject matter or materials included.

\section{References}

1. Huehns ER, Lutzner M, Hecht F. Nuclear abnormalities of the neutrophils in D1 (13-15)-trisomy syndrome. Lancet 1964;1:589-590.

2. Kahwash BM, Nowacki NB, Kahwash SB. Aberrant (barbed-wire) nuclear projections of neutrophils in trisomy 18 (Edwards syndrome). Case Rep Hematol 2015;2015:163857.

3. Lakovschek IC, Streubel B, UIm B. Natural outcome of trisomy 13, trisomy 18 , and triploidy after prenatal diagnosis. Am J Med Genet A 2011;155:26262633. 